\title{
Support for practising - and researching - bioethics
}

The Cambridge Textbook of Bioethics

Peter A. Singer and A.M. Viens, editors

Cambridge University Press; 2008.

538 pp US $\$ 67.50$

$\mathrm{T}$ he task of a textbook reviewer may not have changed much since 1892, when Canadian physician William Osler wrote his monumental work, The Principles and Practice of Medicine, one of the first texts that organized internal medicine as an intellectual discipline. A 19th century reviewer of the Osler textbook might have asked 3 key questions about that work: Did it achieve its goal of comprehensively structuring and describing the field of internal medicine? Did it succeed by offering practical help to doctors? And did it open the possibility of expanding and developing internal medicine rather than merely cataloging the field as it existed in 1892? Retrospectively, in the case of Osler's textbook, the answer to these 3 questions is a resounding "Yes." Turning our gaze prospectively to the book under review, The Cambridge Textbook of Bioethics, we can address 3 similar questions: How well is the book organized? Does it have practical value? What will be its long-range impact?

Organizing the field: In structuring and reconceptualizing the field of bioethics, the editors have organized the textbook into the following major sections: end-of-life care, genetics and biotechnology, research ethics, health systems, global health ethics, pediatrics and pregnancy issues, religious and cultural perspectives, and clinical ethics. Each section is introduced with an essay from such distinguished editors as James Tulsky, John Lantos, Solomon Benatar, Susan MacRae, Richard Ashcroft and Joseph Boyle. The section editors include physicians, nurses, philosophers and legal scholars, who reflect the strong interdisciplinary perspective of the text. The book is also international in its scope, and while the US and Canadian perspectives predominate, chapter contributors come from 8 other countries, including the
United Kingdom, Australia, China, Israel and Syria. Although each section is superb, I especially liked Section II ("End of Life Care"), which includes contributions from such distinguished scholars as Bernard Dickens, Douglas Martin, Robert Pearlman and Robert Arnold, and Section IX ("Religious and Cultural Perspectives in Bioethics"), which includes chapters on Hindu, Sikh, Buddhist and Aboriginal bioethics in addition to chapters on Catholic, Protestant, Islamic and Jewish bioethics.

Practical value: The Cambridge textbook aims to be practical, both clinically and pedagogically. As the editors state, "The goal is to support performance (i.e., what clinicians actually do) by helping to develop awareness and skills in the normative considerations that affect clinical and research practice." To achieve this goal, each chapter begins with the presentation of a clinical case and ends with the resolution of that case. The body of each chapter includes careful consideration of the bioethical question, its relation to legal, philosophical and theological concerns and consideration of how the actual problem should be approached by practitioners to improve patient care. The editors embrace a broad range of ethical approaches to resolve practical dilemmas, including applied ethics, case-based ethics and principalism, and show throughout the book how the integration of these different methods may be more useful than relying on a single, particular model. The book aims to reach both practising clinicians (physicians, nurses and allied health professionals) and teachers of bioethics in medical and nursing schools, residency programs, and in philosophy and theology programs.

Potential impact: Very few textbooks survive as long as the Osler textbook of medicine, which lasted for more than 3 generations and 25 editions. Nevertheless, I anticipate that The Cambridge Textbook of Bioethics will be the first of a series of editions and will be used and enjoyed by clinicians and bioethics students for many years to come.

In the summer of 1897, Frederick Gates, John D. Rockefeller's philanthropy adviser, spent his summer vacation reading the entire 1000 page Osler textbook. In his autobiographical memoir, Gates recalls, "I saw clearly from the work of this able and honest man, perhaps the ablest physician of his time, that medicine had in fact, with four or five exceptions, no cures for disease .... I had begun to realize how woefully neglected had been the scientific study of medicine in the United States ... To this end, it seemed to me an institute of medical research ought to be established in the United States ... I brought my Osler into the office ... and there I dictated for Mr. Rockefeller's eyes a memorandum."'

The Gates memo was the seed from which the Rockefeller Institute grew and this, in turn, gave rise to the private and public support of medical research in the United States. I can envision that The Cambridge Textbook of Bioethics might encourage a similar kind of support for bioethics research that will broaden and deepen the intellectual base and the clinical utility of this new field.

\section{Mark Siegler MD \\ Director \\ MacLean Center for Clinical Medical Ethics \\ University of Chicago \\ Chicago, Illinois}

\section{REFERENCE}

1. Gates FT. Chapters in my life. New York City (NY): The Free Press; 1977.

In the 1980s, Dr. Siegler directed Dr. Singer's fellowship program in clinical medical ethics, and during the 1980s and 1990s, they collaborated on many papers. They are still in contact. 